OUR ASTRONOMICAL COLUMN.

An Earth-efFect on the Sun.-A shift of the lines in the solar spectrum towards the red with reference to the arc-lines which varies with distance from the centre of the disc observed at the soilar observatory at Kodaikánal has been attributed to an earth-effect, and an attempt is being made to unravel the problem by observing the spectrum of Venus at different phases. The method of the scheme is to find if a similar shift is apparent in the spectrum of Venus when illuminated by the light of the solar hemisphere which is turned $90^{\circ}$ or more from the earth, in which case the phenomenon of the shift of the lines, not being peculiar to the part of the sun towards us, could not be ascribed to a terrestrial cause.

Dr. Gilbert Walker has suggested that the law of increase of shift of the solar lines from the centre of the disc to the limb as observed at Kodaikanal might be explained on the hypothesis of a constant "relativity" shift towards red, combined with a shift towards violet, due to a radial outflow of the gases of the reversing layer.

In his report of the observatory for the year Igis Mr. Evershed gives the recent progress of the investigation by saying that the Venus plates taken about the western elongation of the planet when the angle Venus-sun-earth was about $45^{\circ}$ yield slightly smaller values of the shifts, and there is a progressive diminution of wave-length as the angle at the sun increases. When this angle exceeds $90^{\circ}$ the displacements sunarc all have the minus sign--that is, the solar lines reflected by Venus are shifted to violet instead of to red with reference to the iron arc. Mr. Evershed adds that the result of the Venus work seems to dispose finally of the possibility that the solar lineshifts are due to the gravitational effect resulting from Einstein's generalised relativity hypothesis, and thinks the facts undoubtedly show earth-effect, whether the shift is interpreted as motion or otherwise. But he thinks it is very desirable that confirmation of these results should be obtained independently by other observers.

The Lunar Atmospheric Tide.-The object of a paper read by Dr. S. Chapman before the Royal Meteorological Society in February last, and published in the April issue of the Quarterly Journal of that Society, was to discuss certain recent determinations of the lunar diurnal variation of barometric pressure for Batavia and Hong Kong. Opportunity was taken to refer to previous work and to review the present state of knowledge of the subject. The lunar daily barometric variation at Batavia has a semi-amplitude of $0.065 \mathrm{~mm}$. of mercury, which may be compared with the semi-amplitude of $0.0090 \mathrm{~mm}$. found by Dr. Chapman last year from sixty-four years' observations at Greenwich. This lunar variation is purely semi-diurnal, no appreciable diurnal component being observable. It is independent of lunar phase, and the data are inconclusive as regards the influence of lunar distance; for, though the amplitude is probably larger at perigee than at apogee, the exact ratio is not yet determined. The slight variation of amplitude depending on the moon's declination which tidal theory predicts is not detectable, but a marked seasonal variation affecting both amplitude and phase is rather surprising. The discussion of these results for various stations shows that the amplitude diminishes from the equator approximately as the fourth power of the cosine of the latitude. These departures from theory in the value of this quantity, which, it will be realised, is very small and difficult of detection, lead to the conclusion that the lunar atmospheric tide is not a simple tidal phenomenon, but is complicated by other causes.

NO. 2588 , vOL. IO3]
THE DATE-PALM SUGAR INDUSTRY OF INDIA.

UT of India's annual output of some 3,000,000 tons of crude sugar it is estimated that about Io per cent. is derived from palms and about 4 per cent. from the date-palm, cultivated for this purpose in Bengal. Palm-sugar is obtained by making an incision in the soft upper part of the stem, whereby certain pathological changes appear to be induced, which result in an outflow of liquid containing sucrose. This liquid is collected and concentrated in earthenware pots until it is of such a consistence as to solidify on cooling, when it constitutes "gur" or " jaggery," a crude, dark brown sugar for which there is a considerable demand in India. "Gur" is sometimes treated in native-owned refineries for the production of a more or less white sugar by placing it in baskets with pots underneath, into which the molasses drains, the removal of the molasses being facilitated by placing on the surface of the "gur" a layer, 4 in. or 5 in. deep, of water-weed (Vallisneria spiralis) to supply moisture.

This process of producing palm-sugar has been investigated recently by $\mathrm{Mr}$. $\mathrm{H}$. E. Annett, agricultural chemist to the Government of Bengal, ${ }^{1}$ chiefly with the object of placing the industry in a better position to compete with sugar and molasses imported from Java.

In the second memoir $\mathrm{Mr}$. Annett gives the results of the investigations he has made with the view of finding means of avoiding loss of sucrose, improving the quality of the crude sugar, modernising the refining process, and economising in fuel. There may be a considerable loss of sucrose by inversion while the juice remains in the collecting pots. This is reduced to some extent by the native process of smoking the insides of the collecting pots before use, but it can be further reduced by coating the insides of the pots with lime-wash. By this use of lime the yield of "gur" can probably be increased by about 20 per cent.

The liquid as it exudes from the trees is normally water-white, but rapidly darkens on boiling, due mainly to the action of alkaline constituents of the juice on the reducing sugars. This darkening can be avoided by neutralising the juice with an acid before boiling down. Suitable acid liquids are limejuice, alum solution, or aqueous extract of tamarind fruits.

A considerable item in the cost of producing palmsugar is fuel, which in some of the areas is scarce and dear. Trials of an imported American maplesugar plant as a means of economising fuel gave disappointing results, but it has been found possible to make various suggestions regarding concentration pans, the construction of the native furnace, and possible waste combustible materials, the adoption of which would lead to a reduction in the fuel costs.

"Gur" made from juice collected in limed pots, and carefully concentrated after neutralisation with acid, was of good colour, and gave the satisfactory yield of 59 per cent. of refined sugar on treatment in a centrifugal machine, whereas from "gur" made bv the native process only 3 I per cent. could be obtained. A thorough trial of centrifugal machines for refining the crude sugar in place of the tedious native process is recommended.

In his first memoir Mr. Annett made the useful suggestion that it might be feasible to set un small central factories for the production of refined palmsugar in suitable areas, supplies of juice being bought

1 Memoirs of the Department of Agriculture in India. Chemical Series vol. ii., No 6, and vol. v., No. ${ }_{3}$. (Calcutta: Tbacker, Spink, and C.. 
from the owners of palm-gardens; but in his second memoir he has regretfully to confess that "such a scheme would be unworkable in practice unless the owner of the plant also had his own trees. Personal experience showed us that one is entirely at the mercy of the cultivator, and no amount of argument will persuade him to sell his juice at a reasonable rate."

\section{SUSSEX NATURAL HISTORY.1}

$T \mathrm{HE}$ Hastings and St. Leonards Natural History Society may be congratulated on the wellsustained number of its members (373), on the smallness of its annual subscription ( $3 s .6 d$.$) , and on the$ interesting character of its journal. It is, in the opinion of many naturalists, disastrous when local societies undertake to publish scientific information important for its novelty. In after-years the duty of reference to such a source may cause students serious inconvenience. The faunistic lists in the present journal so industriously compiled-of Coleoptera by Mr. W. H. Bennett, of Aphididæ by Mr. F. V. Theobald, of Oligochæta by the Rev. H. Friend, and of the local fauna and flora in general by the late memorable Rev: E. N. Bloomfield, Mr. E. A. Butler, Mr. W. Ruskin Butterfield, Mr. Thomas Parkin, and others-will serve to illustrate this point of view. They are, for the most part, of purely local interest, legitimately recorded in the archives now under review. But in a few instances the entries seem less appropriately placed. Thus Mr. Theobald (vol. ii., No. I, p. I5) renames two species of Aphis. Mr. Friend (vol. ii., No. 3, p. I19) gives details of an Oligochæte as a new species, though he mysteriously says that he had "described" it more than a year earlier. Among Hymenoptera Mr. Bloomfield (vol. ii., No. 3 , pl. 9, p. IOI) gives excellent figures of Neurotes iridescens, male and female. assigning them on the following page to "Neurotis iridescens (Enoch)," name of senus and author's name misprinted. Nearly a year later (vol. ii., No. 4, p. I78) that author, the late Mr. Fred Enock, fully describes the genus and the species, both still considered as new, of this interesting addition to the family of Mymaridæ or fairy flies.

Apart, however, from the impolicy of publishing novelties of classification in local records, Mr. Enock's account of the family is well worth reading, as is Mr. Friend's notice of the Oligochreta. In view of the common demand for significant names in biology, he amusingly notes that in these Annelids, named for few setæ, "sometimes the total number of setæ is two thousand, though the worm may not exceed half an inch in length."

In other branches of knowledge things are not always what they are called. In a lecture to which Mr. Anthony Belt, the editor, directs attention, $\mathrm{Mr}$. J. E. Price, a soldier, explains that "smokeless powder" is not a powder at all. This author, speaking in 1912 , suggests that the scientific perfection of arms, by rendering the prospect of war too awful to contemplate, "may materially contribute to the preservation of that peace of nations which is so much desired by every thoughtful man to-day." Meanwhile. some of these "thoughtful men" were engineering a conflict which is reckoned to have cost more than four millions of lives of men, not to speak of heart-aching to millions of women that no one can number.

As might be expected with Mr. Thomas Parkin, 1 Hastings and East Sussex Naturalist, vol. ii., Nos. 1-6; vol. iii.,
No. I (December 31 , 1912-18).

NO. 2588 , VOL. IO3] sometimes as president and always as enthusiastic supporter of the society, the journal may be said to be on the wing with bird-life, and his well-illustrated articles on historic houses-the Grey Friars, Winchelsea, and its rookery (vol. ii., No. 2), Ashburnham Place (vol. ii., No. 4), and Brickwall and Brede Place (vol. ii., No. 6) - must be of continuing interest. In the last he shows how legends may arise. On a vast oak beam there was a great iron hook, of which he said to a companion, "Look where the old lord used to hang his vassals." Lo and behold, "two or three years afterwards I went there again, and the custodian, having forgotten me, repeated my own words as authentic history." Naturally, in speaking of heronries, Mr. Parkin is all in favour of the noble birds, but those who wish to keep goldfish in ornamental waters have been heard to denounce herons as abandoned pirates. There are two sides to many problems, as $\mathrm{Mr}$. Ticehurst shows in regard to the introduction of the little owl (vol. ii., No. 2).

Remarkably full of interest are the papers on Eoanthropus dawsoni by the late much lamented Charles Dawson (vol. ii., Nos. 2 and 4). But here again we must take into account what Mr. Anthony Belt has to say in his article on prehistoric Hastings (vol. iii., No. I, p. 6). Limits of space exclude from notice many other notable essays, such, for example, as that by Prof. Seward on Wealden floras.

\section{NEW IDEALS OF SCIENCE TEACHERS.}

$A$ LITTLE more than a year has now elapsed since the publication of the report of the Government Committee which, with Sir J. J. Thomson as chairman, inquired into the position occupied by natural science in the educational system of Great Britain. In the meantime, the recommendations made in this report have been carefully considered by science teachers and others, and at a conference held on May 3o, under the auspices of the London County Council, with Sir Cyril Cobb as chairman, the general aims of science teaching were freely discussed.

The main fact which seemed to be made clear by the discussion was that the science teacher of the present day must have two well-defined aims: the one to prepare children for the business of life, and the other to prepare them equally well. for the more difficult business of living. On ethical grounds alone there can be no doubt as to which of these is the higher, for "the life is more than meat and the body than raiment." To this we can add that without the meat and raiment and the things of which these are but symbols, life in its broadest, as well as in its more restricted, sense is impossible. Hence these two aims, which appear to some incompatible, or even antagonistic, are in reality convergent, and meet on the common ground of national welfare.

Sir J. J. Thomson, in the opening speech, gave the key-note of the seemingly more ideal theme. Science teaching which is to add to the interests of life and contribute to the joie de vivre by dispelling the boredom of unoccupied leisure must be of the popular kind--that is, stimulating rather than feeding. It must cover a very wide field, and be given in the form of lectures, accompanied, when possible, by practical work of a suitable kind.

Such a course as this, essentially the same for boys and girls up to the age of sixteen, must include biology as well as chemistry, physics, and astronomy, for no general course can be considered complete which does not include the consideration of man in relation to his environment. Moreover, if we are to change a $C_{3}$ population to an Ar nation, we must seek the "elixir 